\title{
Knowledge, self-help and socioeconomic factors in South Asian and Caucasian diabetic patients
}

\begin{abstract}
Aims We carried out a survey of important nonclinical issues including awareness and self-management of diabetes on a group of South Asian and Caucasian patients attending diabetic clinics within a set period.

Methods A structured questionnaire examined various issues including demographics, perceived knowledge and awareness of diabetes, perceived self-help/ support, and psycho-social factors. A total of 500 patients (268 South Asians and 232

Caucasian) took part.

Results Univariate analysis showed significant differences $(P<0.05)$ with various issues including a lower perceived awareness of diabetes and its complications in South Asians, and of the nutritional content of their diet. Asians also appeared to be less worried in the event of missed clinical appointments and if treatment was not strictly adhered to. Conclusions The study provides evidence of the inability of health information systems to convey the importance of diabetic control to the Asian population. In order that this important information reaches the required recipients, more assertive and perhaps more culturally acceptable methods need to be explored.
\end{abstract}

Eye (2004) 18, 509-513. doi:10.1038/sj.eye.6700680

Keywords: Asian; diabetes; self-help; awareness; socio-economic

\section{Introduction}

Roughly $2-4 \%$ of the UK adult population suffer from diabetes and about $5 \%$ of total health-care expenditure is spent on the care of these patients. ${ }^{1}$ Studies in various parts of the

S Pardhan ${ }^{1}$ and I Mahomed ${ }^{2}$

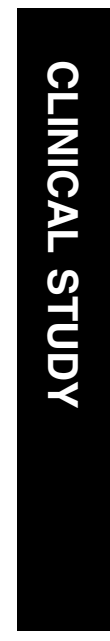

world ${ }^{2-5}$ including the $\mathrm{UK}^{6-10}$ report a higher prevalence of diabetes in Asians from the Indian subcontinent than in other races. The order of increase in prevalence of diabetes in Asians could be as high as four times that of people of European (Caucasian) origin. ${ }^{7}$ Greenhalgh ${ }^{11}$ suggests various hypotheses to explain the high prevalence rates of diabetes in South Asians. Although these factors, embracing nature and nurture, are not mutually exclusive, they probably interact with each other in a complicated and undetermined manner. It is known that adequate control of diabetes is essential if complications are to be reduced. ${ }^{12}$ If patients are to contribute to the effective control of their diabetes, their knowledge, self-caring skills, self-control, and attitude to diabetes are important.

At present, very little is known about Asian patients' attitudes towards self-help and importance of control of diabetes, although some evidence of lower uptake of health service provision by ethnic minorities in the UK has been shown ${ }^{13,14}$ in diabetic clinics, ${ }^{14}$ for coronary artery diseases, ${ }^{15}$ referral rates and attendance in Emergency Departments. ${ }^{16}$ Awareness of the existence and utilisation of community health and social services is also low among Asians. ${ }^{17,18}$ In diabetic patients, Hawthorne ${ }^{19-21}$ reported poorer blood glucose control and lower awareness of diabetes management in a group of Pakistani Moslems. Although a few studies, including those by Hawthorne ${ }^{22}$ and Simmons et al, ${ }^{23}$ examined knowledge of diabetes in Asians and Caucasians, comprehensive comparative data on various other issues including anxiety if hospital appointments were missed and awareness of their diet do not exist. We aim to examine these in addition to the patients' perceived levels of knowledge of diabetes,
${ }^{1}$ Department of Optometry and Ophthalmic Dispensing Anglia Polytechnic

University

Cambridge, UK

${ }^{2}$ Department of Ophthalmology Bradford Royal Infirmary Bradford, UK

Correspondence:

$S$ Pardhan

Department of Optometry and Opthalmic Dispensing Anglia Polytechnic

University

Cambridge CB1 1PT, UK

Tel: + 441223363271 ext 2257

Fax: + 441223417712

E-mail: s.pardhan@

apu.ac.uk

Received: 25 February 2003 Accepted in revised form: 10 June 2003 
including knowledge prior to diagnosis of diabetes and awareness of the possibility of inheritance, etc.

\section{Materials and methods}

\section{Patients}

All consecutive diabetic patients who attended the Outpatients Diabetic Clinic at Bradford Royal Infirmary between March 1996 and December 1997 were invited to participate in the study. A total of 500 eligible patients, of whom 232 were Caucasians, all born in the UK, and 268 of South Asian origin, took part. All Asians were born abroad in Pakistan, India, or Bangladesh and had settled in Bradford. Patients were included if they were over 40 years of age, were diagnosed as diabetic and had not been treated for any other eye diseases. The study was approved by the appropriate Ethical Committee and followed the tenets of the Declaration of Helsinki. Informed consent was obtained from the patients after explaining the aims of the study. None of the patients was seen more than once. Clinical details of the two groups of patients are given in Table 1 .

\section{Methods}

A structured questionnaire was designed using strategies and methodological issues recommended for community-based research within a racial/ethnic minority community. ${ }^{24}$ The questionnaire was based on discussions held with various clinicians and on focus interviews with South Asian subjects. The questionnaire was validated by means of detailed interviews whereby different questions and ways of questioning were investigated and adopted following patients' responses and feedback. Difficult and potentially ambiguous questions were clarified. The questions were also checked for their 'political correctness'. The issues explored are summarised in Table 2. As it is difficult to equate education levels from foreign grades, it was decided to use the age at which full-time education was completed as a better marker. Data on employment (full-time, part-time, homemaker, student, retired) and marital status (married, separated, divorced, widowed, single) were also obtained. Immediate family with diabetes was clarified as either siblings or parents. Awareness of complications of diabetes required the subjects to name the organs that can be affected by diabetes such as eyes, feet, etc. In some questions, a visual analogue scale was used after careful explanation of its use. Each subject was given trial runs on some sample questions until it was deemed that they could perform the test.

The questionnaire was administered in two main Asian languages, Urdu and Hindi, and in English. All the subjects spoke at least one of these languages. No eligible patient refused to take part in the study.

\section{Results}

Univariate analysis results of the survey are shown in Table 2. There were no significant differences in sex or marital status between the two groups. A larger percentage of Caucasians $(67 \%)$ had smaller household structures, that is, of less than three people in the house, compared to Asians (36\%). A significant difference also existed in income levels with 59\% of Asians having an income of less than $£ 7999$ compared to $43 \%$ of Caucasians. In total, $7 \%$ of Caucasians had an income of higher than $£ 15000$ compared to $3 \%$ of Asians. Age at which full-time education was completed was significant as well. A total of $57 \%$ of Caucasians were educated to 16 years and beyond compared to $35 \%$ of Asians.

As Table 2 shows, Asians reported a significantly lower $(P<0.05)$ perceived knowledge of diabetes, awareness of diabetic complications, and awareness of the nutritional content of their diet. They also reported lower importance of keeping clinical appointments and less

Table 1 Clinical and demographic details

\begin{tabular}{|c|c|c|}
\hline & Caucasians $(\mathrm{n}=232)$ & Asians $(\mathrm{n}=268)$ \\
\hline Gender & M: $105(45 \%), F: 127(55 \%)$ & M: $140(52 \%), \mathrm{F}: 128(48 \%)$ \\
\hline Mean age (years) & $\begin{array}{l}\text { Median: } 61.30 \\
\text { (range: } 41-80 \text { ) }\end{array}$ & $\begin{array}{l}\text { Median: } 61.30 \\
\text { (range: } 58-87 \text { ) }\end{array}$ \\
\hline Mean duration (years) & $\begin{array}{l}\text { Median: } 8.00 \\
\text { (range: } 0-35 \text { ) }\end{array}$ & $\begin{array}{l}\text { Median: } 9.73 \\
\text { (range: } 0-29 \text { ) }\end{array}$ \\
\hline Country of birth & UK $(46.4 \%)$ & $\begin{array}{l}\text { India }(8.2 \%), \text { Pakistan }(38.4 \%) \\
\text { Bangladesh }(4.6 \%) \text { Other }(2.4 \%)\end{array}$ \\
\hline Age at diagnosis (years) & $\begin{array}{l}\text { Median: } 50.81 \\
\text { (range: } 23-80 \text { y) }\end{array}$ & $\begin{array}{l}\text { Median: } 50.20 \\
\text { (range: } 19-78 \text { ) }\end{array}$ \\
\hline No. diagnosed before age of 30 years & 3 subjects & 6 subjects \\
\hline Insulin requiring & $134(51 \%)$ & $162(60 \%)$ \\
\hline
\end{tabular}


Table 2 Results of the univariate analysis for the different issues examined

\begin{tabular}{|c|c|c|c|c|c|c|c|c|c|}
\hline Variable & Type & Units/categories & Measure & Caucasian & Asian & Statistic & Value & $d f$ & $\mathrm{p}$-value \\
\hline \multicolumn{10}{|l|}{ Demographic details } \\
\hline \multirow[t]{2}{*}{ Sex } & \multirow[t]{2}{*}{ Categorical } & 1: Male & \multirow[t]{2}{*}{ Frequencies } & 105 & 140 & \multirow[t]{2}{*}{$\chi^{2}$} & \multirow[t]{2}{*}{2.425} & \multirow[t]{2}{*}{1} & \multirow[t]{2}{*}{0.1194} \\
\hline & & 0: Female & & 127 & 128 & & & & \\
\hline \multirow[t]{4}{*}{ Marital status } & \multirow[t]{4}{*}{ Categorical } & 3: Divorced & \multirow[t]{4}{*}{ Frequencies } & 12 & 12 & \multirow[t]{4}{*}{$\chi^{2}$} & \multirow[t]{4}{*}{2.889} & \multirow[t]{4}{*}{3} & \multirow[t]{4}{*}{0.408} \\
\hline & & 2: Widowed & & 30 & 24 & & & & \\
\hline & & 1: Married & & 142 & 181 & & & & \\
\hline & & 0 : Single & & 48 & 51 & & & & \\
\hline \multirow[t]{4}{*}{ Income $(£)$} & \multirow[t]{4}{*}{ Categorical } & $2:>15000$ & \multirow[t]{3}{*}{ Frequencies } & 17 & 10 & $\chi^{2}$ & 12.56 & 2 & 0.0018 \\
\hline & & 1: 8000-15000 & & 83 & 72 & & & & \\
\hline & & $0:<7999$ & & 100 & 160 & & & & \\
\hline & & & Missing data & 32 & 26 & & & & \\
\hline Education age & Categorical & 3: Over 16 & Frequencies & 133 & 96 & $\chi^{2}$ & 25.985 & 2 & 0.0007 \\
\hline (years) & & 1: 14-16 & & 61 & 83 & & & & \\
\hline & & 0: Under 14 & & 35 & 68 & & & & \\
\hline & & & Missing data & 3 & 21 & & & & \\
\hline Household & Category & 2: more than 5 people & Frequencies & 4 & 20 & $\chi^{2}$ & 49.34 & 2 & 0.000 \\
\hline structure & & 1: between 3 and 5 people & & 72 & 148 & & & & \\
\hline & & 0 : less than 3 people & & 156 & 96 & & & & \\
\hline & & & Missing data & & 4 & & & & \\
\hline Awareness of diabetes/ & complications & & & & & & & & \\
\hline Perceived & Continuous & Response ranging not at & Mean & 0.649 & 0.692 & Mann- & 1.469 & 498 & 0.142 \\
\hline possibility of & & all (0) to extremely likely (1) & SD & 0.343 & 0.306 & Whitney & & & \\
\hline inheritance & & & $n$ & 232 & 268 & & & & \\
\hline Perceived & Continuous & Response ranging not at & Mean & 0.605 & 0.476 & Mann- & 5.855 & 497 & 0.000 \\
\hline knowledge & & all $(0)$ to very & SD & 0.238 & 0.251 & Whitney & & & \\
\hline of diabetes & & knowledgeable (1) & $n$ & 231 & 268 & & & & \\
\hline & & & Missing data & 1 & & & & & \\
\hline Perceived & Continuous & Response ranging from & Mean & 0.203 & 0.224 & Mann- & -1.107 & 496 & 0.309 \\
\hline knowledge of & & not at all (0) to very & SD & 0.229 & 0.238 & Whitney & & & \\
\hline $\begin{array}{l}\text { diabetes prior to } \\
\text { diagnosis }\end{array}$ & & knowledgeable (1) & $n$ & 231 & 267 & & & & \\
\hline Awareness of & Categorical & 3: three+ & Frequencies & 166 & 158 & $\chi^{2}$ & 11.23 & 3 & 0.00365 \\
\hline diabetic & & 2: two & & 51 & 72 & & & & \\
\hline complications: & & 1: one & & 15 & 38 & & & & \\
\hline $\begin{array}{l}\text { no. of possible } \\
\text { complications }\end{array}$ & & 0 : none & & 0 & 0 & & & & \\
\hline Perceived & Continuous & Response ranging from & Mean & 0.710 & 0.539 & Mann- & 7.624 & 496 & 0.000 \\
\hline awareness of & & not all (0) to very & SD & 0.241 & 0.255 & Whitney & & & \\
\hline nutritional & & aware (1) & $n$ & 230 & 268 & & & & \\
\hline content of diet & & & Missing data & 1 & & & & & \\
\hline GP as the best & Categorical & 1: Yes & Frequencies & 176 & 200 & $\chi^{2}$ & 0.163 & 1 & 0.686 \\
\hline $\begin{array}{l}\text { source of } \\
\text { information }\end{array}$ & & 0: No & & 56 & 68 & & & & \\
\hline Perceived & Continuous & Response ranging & Mean & 0.854 & 0.781 & Mann- & 3.783 & 496 & 0.00017 \\
\hline importance of & & from not at all $(0)$ & SD & 0.202 & 0.227 & Whitney & & & \\
\hline keeping clinic & & to very important (1) & $n$ & 231 & 267 & & & & \\
\hline appointments & & & Missing data & 1 & 1 & Mann- & 2.766 & 485 & 0.005 \\
\hline Perceived anxiety & Continuous & Response ranging & Mean & 0.607 & 0.536 & Whitney & & & \\
\hline if treatment is & & from not at all $(0)$ & SD & 0.305 & 0.262 & & & & \\
\hline not adhered to & & very anxious (1) & $n$ & 222 & 265 & & & & \\
\hline & & & Missing data & 10 & 3 & & & & \\
\hline Perceived & Continuous & Response ranging & Mean & 0.713 & 0.575 & Mann- & 6.379 & 496 & 0.000 \\
\hline importance of & & from not at all (0) & SD & 0.238 & 0.245 & Whitney & & & \\
\hline control of & & to very important (1) & $n$ & 230 & 268 & & & & \\
\hline diabetes & & & Missing data & 2 & & & & & \\
\hline
\end{tabular}

$p$-values in bold denote significant effects. 
Table 3 Multivariate analysis of factors which showed significance in Table 2

\begin{tabular}{|c|c|c|c|}
\hline & \multicolumn{3}{|c|}{ Independent variables } \\
\hline & Race & Income & Education level \\
\hline Perceived knowledge of diabetes & $\mathrm{P}=0.000(\beta=-0.225)$ & $P=0.283(\beta=0.052)$ & $\mathrm{P}=0.0045(\beta=0.138)$ \\
\hline $\begin{array}{l}\text { Awareness of diabetic complications: no. } \\
\text { of possible complications }\end{array}$ & $\mathrm{P}=0.001(\beta=-0.154)$ & $\mathrm{P}=0.95(\beta=0.003)$ & $\mathrm{P}=0.015(\beta=0.12)$ \\
\hline Perceived awareness of nutritional content of diet & $\mathrm{P}=0.000(\beta=-0.325)$ & $P=0.665(\beta=0.021)$ & $\mathrm{P}=0.355(\beta=0.044)$ \\
\hline Perceived importance of keeping clinic appointments & $P=0.000(\beta=0.161)$ & $P=0.345(\beta=0.047)$ & $P=0.06(\beta=-0.092)$ \\
\hline Perceived anxiety if treatment is not adhered to & $\mathrm{P}=0.074(\beta=-0.088)$ & $\mathrm{P}=0.938(\beta=0.003)$ & $\mathrm{P}=0.0617(\beta=0.095)$ \\
\hline Perceived importance of control of diabetes & $\mathrm{P}=0.00(\beta=-0.272)$ & $P=0.47(\beta=0.035)$ & $\mathrm{P}=0.302(\beta=0.050)$ \\
\hline
\end{tabular}

anxiety if treatment was not adhered to as well as lower importance of control of the diabetes. No significant differences existed in knowledge of diabetes prior to diagnosis.

Significant dependent variables, such as awareness of diabetes and importance of keeping clinical appointments, could be influenced by other variables including socioeconomic and educational status differences between the two groups. We carried out multivariate analysis on factors that showed to be significant in the univariate analysis in Table 2 . These are shown in Table 3 and were carried out to examine the contributions of race, education age, and income levels. Race showed significance with all the issues examined except 'perceived anxiety if treatment was not adhered to', although this was significant to $93 \%$. The level of education was significant for some issues, while income level did not show significance with any of the issues examined.

Some limitations of the study need to be acknowledged. In cases where perceived knowledge and awareness have been examined, we have to rely on the patient's ability to report accurately. In some cases, this may be over- or underestimated, for example, Asians may be more aware of how little they know, whereas the Caucasian population may be giving themselves more credit. Asians reported a lower awareness of diabetes and this was also confirmed by their identification of a lower number of named organs that could be affected by diabetes. Although racial differences in responses to the technique may have existed to an extent, we do not believe that it influenced the results a great deal.

\section{Discussion}

The study shows a lack of understanding of diabetes and its complications by one racial group. Undoubtedly, various issues interlink with each other in a complicated and, at present, rather undetermined manner, to produce an overall picture of lower awareness and self-help in the South Asian population. Although genetic effects may play a role in the higher prevalence of diabetes in the Asian population, ${ }^{25}$ lifestyle issues such as exercise are also very important ${ }^{26,27}$ and sedentary lifestyles may place Asians in the high-risk category. ${ }^{28,29}$ Although information to promote increased physical activity and control obesity has been promoted by health information systems, this study highlights a lack of understanding of these important issues in Asians. In addition, a lower awareness of the nutritional content of the diet was demonstrated. We hypothesise that various issues, including inadequate or inappropriate manner of dissemination of health information as well as the inability of the patients to uptake and retain the important information are responsible.

In order to ensure dissemination of important information, cultural and religious influences need to be understood. Language barriers would possibly play a major role. ${ }^{30}$ The patients' having to rely on relatives or interpreters may lead to information being lost or changed. A study by Ebden et $a^{31}$ claimed that $16-39 \%$ of the simplest questions can be mistranslated by relatives. Communication difficulties may also make it difficult to rearrange appointments. Religious obligations, such as fasting, would make control of diabetes more difficult. ${ }^{32}$ Previous studies have shown that, when communication problems are overcome and people are approached in a culturally sensitive way, they are receptive to advice that advocates changes in lifestyle and the use of preventative services. ${ }^{33}$ Although this may be difficult, especially for older females, for example, written information in a native language would not be appropriate for people who are illiterate, other methods, such as pictorial flashcards, have been used in other parts of the country. ${ }^{21}$ Link-workers who explain reasons for regular appointments and provide encouragement would benefit. ${ }^{13}$ Although quite a number of these approaches are currently being employed in different parts of the country, the results from this study suggest that fundamental differences in important diabetes-related issues between Asian and Caucasian patients still exist. 


\section{References}

1 British Diabetic Association. Counting the Cost: the Real Impact of Non-insulin Dependent Diabetes. King's Fund: London, 1996.

2 Poon-King T, Henry MV, Rampersand F. Prevalence and natural history of diabetes in Trinidad. Lancet 1968; I: 155-160.

3 Jackson WPU. Epidemiology of diabetes in South Africa. In: Miller M, Bennett PH (eds). Advances in Metabolic Disorders, Vol 9. Academic Press: New York, 1978, pp 111-146.

4 Zimmet P, Taylor R, Ram P, King H, Sloman G, Raper LR et al. Prevalence of diabetes and impaired glucose tolerance in the biracial (Melanesian and Indian) population of Fiji: a rural-urban comparison. Am J Epidemiol 1983; 118: 673-688.

5 McKeigue PM, Miller GJ, Marmot MG. Coronary heart disease in South Asians overseas - a review. J Clin Epidemiol 1989; 42: 597-609.

6 McKeigue P, Sevak L. Coronary Heart Disease in South Asian Communities: A Manual for Health Promotion. Health Education Authority: London, 1994.

7 Mather HM, Keen H. The Southall diabetes survey: prevalence of known diabetes in Asian and Europeans. BMJ 1985; 291: 1081-1084.

8 Samanta A, Burden AC, Fent B. Comparative prevalence of non-insulin dependent diabetes mellitus in Asian and White Caucasian adults. Diab Res Clin Pract 1987; 4: 1-6.

9 Simmonds D, Williams DRR, Powell MJ. Prevalence of diabetes in a predominantly Asian community: preliminary findings of the Coventry diabetes study. BMJ 1989; 289: $18-21$.

10 Dodson PM, Krizinger EE, Clough CG. Diabetes mellitus and retinal vein occlusion in patients of Asian, West Indian and White European origin. Eye 1992; 6: 66-68.

11 Greenhalgh PM. Diabetes in British South Asians: nature, nurture, and culture. Diab Med 1997; 14: 10-18.

12 Aiello LP, Cahill MT, Wong JS. Systemic considerations in the management of diabetic retinopathy. Am J Ophthalmol 2001; 132: 760-776.

13 Whitemeans SI. Conceptualising race in economic models of medical utilization - a case study of community-based elders and the emergency room. Health Serv Res 1995; 30: 207-223.

14 Hawthorne K. Accessibility and use of health care services in the British Asian Community. Fam Pract 1994; 4: 453-459.

15 Ford ES, Cooper RS. Racial-ethnic differences in health care utilization of cardiovascular procedures-a review of the evidence. Health Serv Res 1995; 30: 237-252.

16 Baker DW, Stevens CD, Brook RH. Determinants of emergency department use. Are race and ethnicity important? Ann Emerg Med 1996; 28: 677-682.

17 Ritch AES, Ehtisham M, Guthrie S, Talbot JM, Luck M, Tinsley RN. Ethnic influence on health and dependency of elderly inner city residents. J $R$ Coll Physicians Lond 1996; 30: 215-220.
18 Mitchell AA, Sedlacek WE. Ethnically sensitive messengers - an exploration of racial attitudes of healthcare workers and organ procurement officers. J Nat Med Assoc 1996; 88: 349-352.

19 Hawthorne K. South Asian diabetic patients need more education about their illness. BMJ 1997; 314: 1486.

20 Hawthorne K, Tomlinson S. Pakistani Moslems with type 2 diabetes mellitus: effect of sex, literacy skills, known diabetic complications and place of care on diabetic knowledge, reported self monitoring management and glycaemic control. Diab Med 1999; 16: 591-597.

21 Hawthorn K, Mello M, Tomlinson S. Cultural and religious influences in diabetes care in Great Britain. Diab Med 1993; 10: $8-12$.

22 Hawthorne K. Asian diabetics attending a British hospital clinic: a pilot study to evaluate their care. Br J Gen Pract 1990; 40: 243-247.

23 Simmons D, Meadows KA, Williams DRR. Knowledge of diabetes in Asians and Europeans with and without diabetes. The Coventry diabetes study. Diab Med 1991; 8: 651-656.

24 Lillie-Blanton M, Hoffman SC. Conducting an assessment of health needs and resources in a racial/ethnic minority community. Health Serv Res 1995; 30: 225-236.

25 Pearson ER, Hattersley AT. Unravelling the heterogeneity of non-insulin dependent diabetes. J R Coll Physicians Lond 2000; 34(4): 332-335.

26 Perry IJ, Wannnamethee SG, Walker MK, Thompson AG, Whincup PH, Shaper AG. Prospective study of risk factors for development of non-insulin dependent diabetes in middle aged British men. BMJ 1995; 310: 560-564.

27 Manson JE, Nathan DM, Krolewski AS, Stampfer MJ, Willet WC, Hennekens $\mathrm{CH}$. A prospective study of exercise and incidence of diabetes among US male physicians. J Am Med Assoc 1992; 268: 63-67.

28 Samanta A, Burden AC, Jagger C. A comparison of the clinical features and vascular complications of diabetes between migrant Asians and Caucasians in Leicester, UK. Diab Res Clin Pract 1991; 14: 205-214.

29 UK Prospective Diabetes Study (UKPDS) group. Differences between Asian, Afro-Caribbean and White Caucasian Type 2 diabetic patients at diagnosis of diabetes (UKPDS 11). qDiab Med 1994; 11: 670-677.

30 Wright CM. Language and communication problems in an Asian community. J R Coll Gen Pract 1983; 33 101-104.

31 Ebden P, Carey OJ, Bhatt A, Harrison B. The bilingual consultation. Lancet 1988; i: 347

32 Aslam M, Healy MA. Compliance and drug therapy in fasting Moslem patients. J Clin Hosp Pharm 1986; 11: 321-325.

33 Bhopal RS. The inter-relationship of folk, traditional and western medicine within an Asian community in Britain. Soc Sci Med 1986; 22: 99-105. 